\title{
Drying of faecal sludge from VIP latrines through a medium infrared radiation process
}

\author{
SW Mirara', S Septien' ${ }^{1}$ A Singh ${ }^{2}$, K Velkushanova' and CA Buckley ${ }^{1}$ \\ 'Pollution Research Group, University of KwaZulu-Natal, Durban 4041, South Africa \\ ${ }^{2}$ Chemical Engineering, University of KwaZulu-Natal, Durban 4041, South Africa
}

In order to treat faecal sludge from ventilated improved pit (VIP) latrines, eThekwini Municipality (Durban, South Africa) developed an infrared dryer, 'LaDePa' (Latrine Dehydration Pasteurization). Parameters that influence its operation were investigated using a laboratory-scale replica of the full-scale machine. For this, faecal sludge collected from VIP latrines was pelletized and dried under different operating conditions. Drying curves were obtained by plotting medium wave infrared intensity (MIR), height of emitters above the belt, air flowrate and pellet diameter against the residence time. These curves were then used to determine the drying rate and energy consumption. The results show that the drying rate increased while the energy consumption decreased by increasing the power of the MIR emitters and decreasing the size of the pellets. For example, the drying time to get a moisture content of $0.8 \mathrm{~g}$ water/g dry solid was shortened from 27 to 6 min while the energy consumption for this reduced from 1.5 to $0.8 \mathrm{kWh}$ after increasing the MIR power from 1.5 to $3.3 \mathrm{~kW}$. Similar drying curves were obtained by varying the distance between the pellets and MIR emitters, and adjusting intensity of the MIR radiation to obtain the same temperature in the drying zone. It was also observed that higher airflow rates enhanced mass transfer rates, but led to a cooling effect. No effect on the drying rate was observed after pre-drying the sludge or adding sawdust. The study shows that for the process to be efficient, the MIR intensity should be high enough for fast drying to occur $\left(T \geq 150^{\circ} \mathrm{C}\right)$, but without causing thermal degradation $\left(T \leq 220^{\circ} \mathrm{C}\right)$. The height of emitter above the belt and the pellet size should be as small as possible $(8 \mathrm{~mm})$; airflow rate should be optimised to maximize the mass transfer rate and minimize the cooling effect.

\section{INTRODUCTION}

After its creation in 1999, the eThekwini Municipality (KwaZulu-Natal Province, South Africa) inherited over 60000 ventilated improved pit latrines (VIP) latrines. In 2009, the municipality set out to empty over 35000 pits which were already full. A challenge of this operation was the safe disposal of the sludge (Bhagwan et al., 2008; Still and Foxon, 2012)

Several options exist in dealing with full pits. The traditional option was to cover the pit and dig a new one. Alternatively, an adjacent pit would be dug and the content of the full pit transferred to the new pit. These two options are however not applicable in urban and peri-urban areas due to a high human density and the lack of unoccupied land (Still and Foxon, 2012).

The other option is to empty the pits and dispose of or recycle the sludge. Treatment of sludge can be done by anaerobic digestion to produce biogas (Arthur et al., 2011), conventional treatment in wastewater treatment works, use of black soldier flies (Diener et al., 2011; Li et al., 2011), and deep row entrenchment and composting (Still and Foxon, 2012). Other options are conversion by thermochemical processes such as pyrolysis, combustion or gasification (Williams, 2013), and hydrothermal processes such as hydrothermal carbonization and supercritical oxidation (Sevilla and Fuertes, 2009).

In the eThekwini Municipality, the initial idea was to treat the sludge emptied from pit latrines in wastewater treatment works. This, however, caused overloading, leading to the failure of the plant. The eThekwini Municipality had to seek an alternative solution, and together with its industrial partners, came up with a new initiative, the 'Latrine Dehydration and Pasteurization' (LaDePa) process. The LaDePa machine pelletizes faecal sludge; the pellets are then dried and pasteurised by use of MIR radiation. The plant is powered by a diesel generator, which provides waste heat for the pre-drying stage. The sludge, after treatment in the LaDePa process, is a material that can be used as soil conditioner or fertilizer (depending on nutrient content) in agricultural production or that could be incinerated for energy generation. The LaDePa machine is located within the municipality at Tongaat Wastewater Treatment Works, which is about $37 \mathrm{~km}$ north of Durban.

Infrared radiation may be classified into three categories based on the radiation wavelength: near infrared (NIR) with a wavelength between 0.75 and $3.00 \mu \mathrm{m}$; medium-wave infrared (MIR) with a wavelength between 3.00 and $25 \mu \mathrm{m}$; far infrared (FIR) with a wavelength between 25 and $100 \mu \mathrm{m}$. Infrared (IR) drying has been successfully used in various applications such as wood processing (Cserta, 2012; Ratti and Mujumdar, 1995) and food processing (Krishnamurthy et al., 2008), among others. IR technology has various advantages over the traditional hot-air convective drying technologies. It has a higher efficiency in converting electrical energy into heat energy. An example of this is given in the modelling of an IR dryer where high efficiencies of between 73 and $99 \%$ were obtained (Mongpraneet et al., 2004). In a study on the use of a combined IR and hotair dryer for vegetables, it was found that the energy requirement was reduced by $63 \%$ compared

\section{CORRESPONDENCE}

S Septien

EMAIL

Septiens@ukzn.ac.za

\section{DATES}

Received: 17 September 2019

Accepted: 2 June 2020

\section{KEYWORDS}

drying

medium infrared radiation

VIP sludge

LaDePa

\section{COPYRIGHT}

(C) The Author(s)

Published under a Creative

Commons Attribution 4.0

International Licence

(CC BY 4.0) 
to hot air when used alone (Hebbar et al., 2004). IR dryers are usually more compact than convective-dryers, therefore their overall footprint is lower. They are also simpler to control. Among the disadvantages, IR dryers are difficult to scale-up, can hardly process thick materials and present a high potential for fire hazards (Ratti and Mujumdar, 1995).

IR intensity and drying time have the greatest influence on the process. Increasing the emitter power from $40 \mathrm{~W}$ to $100 \mathrm{~W}$ decreased the drying time by half (Mongpraneet et al., 2004). To reduce the moisture content of onion slices to $0.06 \mathrm{~g}$ water/g dry matter at emitter intensities of 300,400 and $500 \mathrm{~W}$, the required drying time was 9, 7 and 4 min respectively (Sharma et al., 2005). As could be expected, drying time depends on the thickness of the material. In an investigation of drying bananas, slices of thickness 2, 3 and $4 \mathrm{~mm}$ were dried using a FIR heater rated $200 \mathrm{~W}$. It was found that to reduce the moisture content from 3.0 to $0.07 \mathrm{~g}$ water/g dry solid, the $4 \mathrm{~mm}$ thick slices took the longest time (Swasdisevi et al., 2007). Drying of potato slices of thickness of 4, 6 and $8 \mathrm{~mm}$ was investigated using a vacuum FIR dryer at temperatures of 120,140 and $160^{\circ} \mathrm{C}$. It was found that $4 \mathrm{~mm}$ samples dried the fastest, followed by $6 \mathrm{~mm}$ slices (Liu et al., 2014).

There is no reported study on drying of faecal sludge using infrared radiation. The LaDePa process is an innovative process; thus there was a need to understand the phenomenology and parameters that influence the process, which would help to improve and optimise the process. This study was carried out using a laboratory-scale $\mathrm{LaDePa}$ plant, in order to investigate the parameters that have the greatest influence on the process. This involved drying of faecal sludge obtained from VIP latrines at varying MIR intensity, emitter height and airflow rate. The effect of the diameter of pellets, pre-drying of the sludge and addition of sawdust to the faecal sludge were also investigated to understand their influence on the drying kinetics.

\section{MATERIALS AND METHODS}

\section{Feedstock}

The feed material for the experiments was faecal sludge that was obtained during the pit emptying of ventilated improved pit (VIP) latrines, within the eThekwini Municipality, Durban, South Africa. The sample used was a mixture of sludge from different sections of a pit, in order to give an average representation of the pit contents. In total six $20 \mathrm{~kg}$ buckets were obtained. In the laboratory, the sludge was firstly sieved through a $5.6 \mathrm{~mm}$ grid to remove trash, such as polythene bags, plastics, clothes, metal cans and other domestic waste, which could hinder the extrusion process. The resultant sludge made up two full $20 \mathrm{~kg}$ buckets. Sawdust was then added to most of the sludge samples ( $4 \%$ of the total mass), in order to facilitate the formation of uniform pellets (Septien et al., 2018). About $2 \mathrm{~kg}$ of sample was left as is, to compare the drying behaviour of the sludge with and without sawdust. Sludge without sawdust could still be formed into pellets, but this operation was more laborious for the production of pellets with a defined cylindrical shape. The samples were stored in a cold room at a temperature of $4^{\circ} \mathrm{C}$ for analysis, in order to preserve their properties.

\section{Experimental set-up}

\section{Laboratory-scale LaDePa machine}

The laboratory-scale LaDePa machine is a replica of the full-scale prototype installed in the eThekwini Municipality, Durban, South Africa, with a size reduction of approximately 10:1. It is composed of a drying section and an extrusion section. The laboratory scale LaDePa is as shown in Fig. 1 while the full-scale plant is shown in Fig. 2. Comparison in terms of size of the laboratory and full-scale LaDePa machines is given in Table 1 .
Table 1. Comparison between the laboratory- and full-scale LaDePa

\begin{tabular}{lcc}
\hline Feature & $\begin{array}{c}\text { Full-scale } \\
\text { LaDePa }\end{array}$ & $\begin{array}{c}\text { Laboratory-scale } \\
\text { LaDePa }\end{array}$ \\
\hline Belt width $(\mathrm{mm})$ & 950 & 250 \\
Belt aperture opening $(\mu \mathrm{m})$ & 300 & 200 \\
Heated width $(\mathrm{mm})$ & 1350 & 220 \\
Heated length $(\mathrm{mm})$ & 11000 & 880 \\
Number of MIR emitters & 3 & 2 \\
MIR power $(\mathrm{kW})$ & 48 & 3.7 \\
Blower power $(\mathrm{kW})$ & 5.5 & 0.75 \\
\hline
\end{tabular}

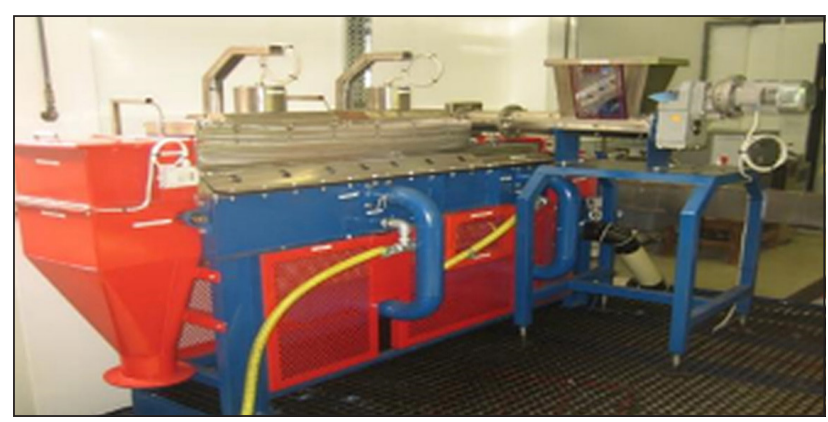

Figure 1. Photograph of the laboratory-scale LaDePa



Figure 2. Photograph of the full-scale LaDePa

The drying section is composed of a porous steel belt, two medium-wave infrared (MIR) emitters, a vacuum system and a discharge hopper. The steel belt is driven by rollers while its tracking is regulated using compressed air. During operation, pellets produced by the extruder are deposited onto the belt and then conveyed into the heating zone where they are exposed to thermal radiation emitted by the two successive MIR emitters. The processed pellets are collected at the discharge hopper. A vacuum under the belt, created by a blower, induces airflow in the heating zone thus removing the evaporated moisture and enhancing the drying process. A damper valve is placed in the pipe connecting the vacuum chamber and the blower in order to control the suction airflow rate through the machine. A schematic diagram of the laboratory-scale LaDePa is shown in Fig. 3.



Figure 3. Schematic diagram of the LaDePa process 




Figure 4. Hand-held capillary extruder and plates used to vary extrusion size

\section{Extrusion of pellets}

The screw extruder from the LaDePa prototype faced several technical challenges. Therefore, it could not be used in this study and pellets were produced using a hand-held capillary extruder, shown in Fig. 4. This device is composed of a polyvinyl chloride water pipe with a diameter of $6.4 \mathrm{~cm}$, with connectors on either end. Caps are fitted to both sides using the connecters. One of the caps has an air inlet through a valve. The other has a hole with a diameter of $14 \mathrm{~mm}$ for the extrusion of the material. Plates of 8 , 10 and $12 \mathrm{~mm}$ diameter could be inserted in the inner parts of the cap to vary the diameter of the extrusion hole. Prior to operation, the capillary extruder was filled with sludge and connected to the compressed air line. To extrude, pressure was set between 5 and $10 \mathrm{kPa}$. After filling the tube with faecal sludge and opening the air valve, the compressed air will push the sludge through the extrusion hole through a piston effect.

\section{Temperature measurement}

The drying chamber temperature (drying temperature) was monitored by two thermocouples that were placed below the centre of each MIR emitter, $2 \mathrm{~cm}$ from the edge and $1 \mathrm{~cm}$ above the porous steel belt. In addition, temperatures of the surface and core of the pellets were recorded during some of the tests by placing thermocouples on the surface or at centre of the pellets. The pellets were then followed with the thermocouple within it into the drying zone.

The temperature was measured using k-type thermocouples. This thermocouple has an accuracy of $\pm 1.1^{\circ} \mathrm{C}$ and is able to measure temperatures up to $1260^{\circ} \mathrm{C}$. These characteristics make it suitable to measure temperatures during these experiments. The temperature readings as a function of time were recorded on an Easy - log El USB data logger and the data was transferred to a computer.

\section{Experimental procedure}

The experiments in the laboratory-scale LaDePa involved the study of the following parameters: emitter intensity, MIR height with respect to the belt, and suction airflow rate in the heating zone. For the investigation of each parameter, the residence time was varied by changing the speed of the belt. Belt speed can be varied from 0.03 to $1.5 \mathrm{~m} / \mathrm{min}$, which corresponds to a residence time interval of 40 to $1 \mathrm{~min}$. A summary of the experimental plan is given in Table 2.

Power supply to the emitters was varied using a potential meter dial, which had a range of $0-100 \%$. As displayed in Table 3, the two emitters did not consume the same amount of power for a given dial reading. Therefore, each emitter was set in order to obtain a similar temperature in the drying zone. Three sets of intensities, $30 \%\left(1.5 \mathrm{~kW}\right.$ leading to a temperature of approximately $\left.87^{\circ} \mathrm{C}\right), 50 \%$ $\left(2.4 \mathrm{~kW}\right.$ leading to a temperature of approximately $\left.136^{\circ} \mathrm{C}\right)$ and $80 \%\left(3.4 \mathrm{~kW}\right.$ leading to a temperature of approximately $\left.214^{\circ} \mathrm{C}\right)$, were used.

The distance between the belt and the MIR emitters was varied between 50 and $115 \mathrm{~mm}$. This was achieved by raising or lowering the emitters with respect to the belt. The suction airflow rate was varied by changing the opening angle of the damper valve. The suction airflow rate varied between 8.2 and $18.3 \mathrm{~m}^{3} / \mathrm{s}$ with the latter corresponding to the damper valve being fully open.

Some experiments were performed with pre-dried sludge and sludge without sawdust, in order to determine the effect of initial moisture content and sawdust addition on the drying of the sludge. The pre-dried sludge was obtained by oven-drying a portion of the sample up to a moisture content of $0.598 \mathrm{~g}$ water/g dry solid (37\% wet basis) and mixing it with fresh sludge. The pellet diameters used for the various experiments were 8, 10, 12 and $14 \mathrm{~mm}$.

At the end of each test, samples were recovered and then ovendried at a temperature of $105^{\circ} \mathrm{C}$ for $24 \mathrm{~h}$. Moisture content was then determined on a dry basis by determining the mass of the evaporated moisture divided by the mass of the dry solid. Moisture content was then plotted against time to give the drying curve. The trend line of the drying curve was obtained using Microsoft Excel data treatment option. Thereafter, the drying rate curve was obtained by deriving the drying curve trend line.

Moisture removal was calculated by determining the difference between the initial moisture content and the moisture content at a particular residence time. The data obtained was used to plot a graph of energy consumption during drying as a function of moisture removed from the sample. Energy consumption was calculated by multiplying the emitter power with the residence time.

For each set of conditions during the experiments, three runs were performed and three sets of pellets were collected per run. From the data obtained at given conditions, the mean values were calculated.

Table 2. Summary of the experimental plan

\begin{tabular}{|c|c|c|}
\hline Parameter/variable & Range of operation & Settings used \\
\hline MIR intensity (\%) & 0 to 100 & 30,50 and 80 \\
\hline MIR height (mm) & 50 to 115 & 50,80 and 115 \\
\hline Belt speed (\%) & 0 to 100 & $55,35,30,27.5,26,25$ \\
\hline Belt speed (min) & 0 to 40 & $4,8,12,17,25,40$ \\
\hline Pellet diameter (mm) & 8 to 14 & $8,10,12$ and 14 \\
\hline Airflow suction rate $(\mathrm{m} / \mathrm{s})$ & 8.2 to 18.3 & $8.2,11.1$ and 18.3 \\
\hline
\end{tabular}

Table 3. MIR intensity settings and corresponding drying temperature

\begin{tabular}{lccccc}
\hline \multicolumn{2}{l}{ MIR 1 intensity } & \multicolumn{2}{c}{ MIR 2 intensity } & Temperature range & Average temperature \\
\hline$(\%)$ & $(\mathrm{kW})$ & $(\%)$ & $(\mathrm{kW})$ & $\left({ }^{\circ} \mathrm{C}\right)$ & 87 \\
\hline 25 & 1.5 & 30 & 1.5 & 84 to 91 & 136 \\
43 & 2.4 & 50 & 2.3 & 133 to 140 & 214 \\
70 & 3.2 & 80 & 3.3 & 209 to 220 & 214 \\
\hline
\end{tabular}






Figure 5. Temperature evolution at the surface and core of 8 and $14 \mathrm{~mm}$ pellets as a function of time

\section{RESULTS AND DISCUSSION}

\section{Evolution of pellet temperature during drying}

The thermal behaviour of the sludge during the drying process was investigated by measuring the temperature at the surface and the core of the 8 and $14 \mathrm{~mm}$ pellets. The experiments conducted were at a constant suction airflow rate of $18.3 \mathrm{~m}^{3} / \mathrm{s}$ while the MIR intensity was maintained at $50 \%$. The temperature evolution as a function of time is presented in Fig. 5. The general trend of the curves shows that pellets were heated under the first emitter causing an increase in temperature. Temperature dropped slightly as pellets passed through the region between the two emitters, because of the absence of heating in this zone. Then temperature increased again as pellets were heated under the second emitter.

Temperature at the surface was higher than at the core of both the 8 and $14 \mathrm{~mm}$ diameter pellets, indicating non-isothermal drying. Temperature at the core of the two pellet diameters investigated remained relatively constant at a temperature oscillating between 60 and $70^{\circ} \mathrm{C}$. In contrast, the temperature at the surface of the pellets increased from the first MIR emitter for the 8 and $14 \mathrm{~mm}$ pellets. The temperature at the surface of the $14 \mathrm{~mm}$ pellets followed a similar pattern as the $8 \mathrm{~mm}$ pellets. However, the maximum temperature attained by the $14 \mathrm{~mm}$ pellets was lower than that of the $8 \mathrm{~mm}$ pellets, which could be expected as smaller bodies tend to be heated faster than larger ones. The temperatures exceeding $100^{\circ} \mathrm{C}$, which is the vaporization temperature of water, suggest that the surface of the pellets was completely dried as it also increased rapidly. Note that the evolution of the surface temperature of the $14 \mathrm{~mm}$ pellets under the first MIR emitter exhibited a plateau at a temperature of $80-90^{\circ} \mathrm{C}$.

Temperature at the surface of the $8 \mathrm{~mm}$ pellets reached higher temperatures than the drying temperatures measured in the thermocouples. This could be attributed to a possible higher absorbance of the sludge compared to the material of the thermocouple, and to a larger surface area for the radiation absorption.

\section{Influence of different parameters on drying}

The effect of various parameters that could affect drying were investigated. These include the MIR emitter intensity, the distance between the emitter and the belt surface, the suction airflow rate, the pellet diameter, sludge initial moisture content and addition of sawdust.

\section{Effect of the MIR radiation intensity}

A plot of the drying behaviour of sludge obtained at different MIR intensities are presented in Fig. 6. These experiments were carried out at a suction airflow rate of $18.3 \mathrm{~m}^{3} / \mathrm{s}$, height of emitters above the belt of $115 \mathrm{~mm}$ and with $8 \mathrm{~mm}$ diameter pellets.



Figure 6. Plot of pellets drying behaviour at different MIR intensities

Increasing the MIR emitter intensity caused an increase in the drying temperature (Table 3 ), consequently decreasing the drying time. This is illustrated by a residence time of 6,9 and $27 \mathrm{~min}$, which is required to reduce the moisture content of pellets to $0.8 \mathrm{~g}$ water/g dry solid (37.5\% wet basis) at intensities of $80 \%$ $(3.3 \mathrm{~kW}), 50 \%(2.4 \mathrm{~kW})$ and $30 \%(1.5 \mathrm{~kW})$, respectively. These results are similar to that of other studies, most of them from the food industry (Pan et al., 2008; Sharma et al., 2005).

At a residence time of $12 \mathrm{~min}$ and a temperature of about $214^{\circ} \mathrm{C}$ (MIR intensity of $80 \%$ ), pellets were completely burnt, so moisture content at a residence time higher than $8 \mathrm{~min}$ at this intensity could not be measured. Charring at emitter intensities of $80 \%$ and residence time of $20 \mathrm{~min}$ was observed in a previous experiment, using the laboratory-scale LaDePa with synthetic sludge (Meng et al., 2014).

The drying rate curves at the different emitter intensities are presented in Fig. 7. As expected, the drying rate increased by increasing the MIR intensity. The drying rate remained relatively constant for the pellets processed at an MIR intensity of 30\% at an average of $0.10 \mathrm{~g}$ water/min. This could mean that drying occurred in the constant rate period. On the contrary, the drying rate and moisture content decreased from 0.21 to 0.07 and from 0.40 to $0.08 \mathrm{~g}$ water/min at MIR intensities of $50 \%$ and $80 \%$, respectively. This result demonstrates that the kinetic regime of drying is dependent on the drying rate. At a higher drying rate the moisture at the surface was rapidly depleted leading to the falling rate period being reached much faster. At a slow drying rate, the evaporated moisture from the surface could have been more easily replaced by the moisture diffusing from the core of the particle, thus maintaining the constant rate period. The assumption of a falling rate period during drying at a MIR intensity of $50 \%$ could be corroborated from the temperature measurements in the $8 \mathrm{~mm}$ pellets, where the temperature at the surface increased constantly and rose rapidly above $100^{\circ} \mathrm{C}$, suggesting that the surface was dried relatively fast (refer to previous section). The same observation could be expected for the $8 \mathrm{~mm}$ pellets at a MIR intensity of $80 \%$.



Figure 7. Drying rate as a function of moisture content at different MIR intensities 
Figure 8 presents the energy consumed by the two emitters to remove a given amount of moisture from the $8 \mathrm{~mm}$ pellets at different MIR intensities. The energy required for moisture removal decreased by increasing the MIR intensity. For example, to reduce moisture content to $2.35 \mathrm{~g}$ water/g dry solid (27\% wet basis), the energy consumption was $1.2,1.02$ and $0.65 \mathrm{kWh}$ at 30, 50 and $80 \%$ MIR intensity, respectively. This implies that the process has a higher energy efficiency while operating at higher MIR intensities. This result could be due to bound moisture being evaporated easily at higher heating flux. An example of this would be the intracellular moisture that may require a high-energy input to be released after breaking the cell wall.

Moreover, the rate of heat transfer should be higher at higher heating flux, so increasing the drying efficiency.

\section{Effect of the distance between the emitters and the conveyor belt}

To study the effect of the distance between the emitter and the pellets, the height of the emitters above the porous steel belt was varied, whilst maintaining a constant temperature above the belt of about $136^{\circ} \mathrm{C}$. This was achieved by reducing or increasing the MIR intensity as the height of emitters above the belt was reduced or increased. The suction airflow rate was kept at $18.3 \mathrm{~m}^{3} / \mathrm{s}$ and the pellet diameter was $8 \mathrm{~mm}$. The drying curves obtained after varying the height of the emitters are presented in Fig. 9. The results show that, at constant drying temperature, the height of the MIR above the belt did not significantly influence the drying curve. Therefore, similar drying rates can be obtained at different emitter heights, as long as the drying temperature is the same. This implies that the reduction of emitter height would minimize the power consumption to dry the material up to a certain moisture content and consequently reduce the operating costs.

Figure 10 shows the moisture removed from the pellets versus the energy consumed at different emitter heights above the belt. At a

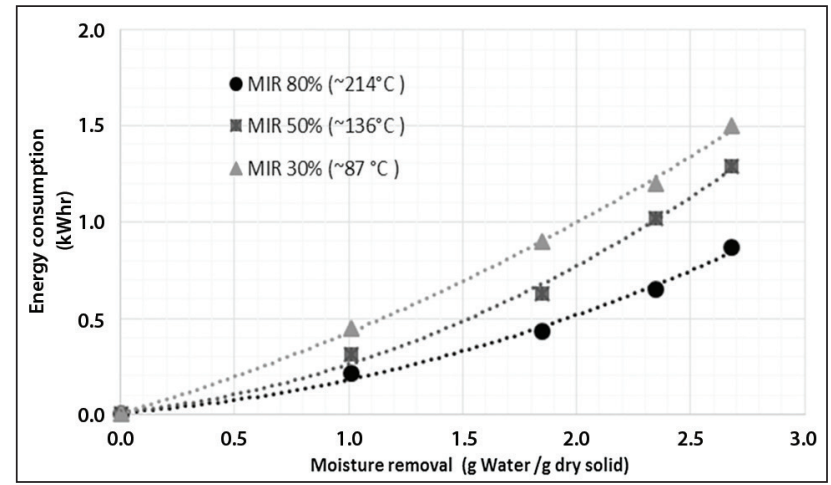

Figure 8. Energy consumption as a function of moisture extraction at different MIR intensities

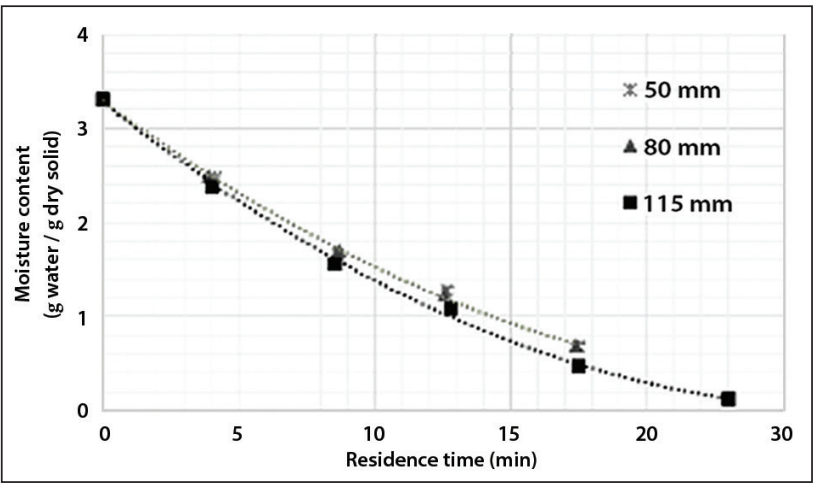

Figure 9. Drying curves at different emitter heights above the belt (MIR intensity varied to maintain a constant temperature above the belt) height of $115 \mathrm{~mm}$ above the belt, more energy is used compared to heights of $50 \mathrm{~mm}$ and $80 \mathrm{~mm}$, particularly after removing $1.5 \mathrm{~g}$ water/g dry solid. The higher energy consumption of the $115 \mathrm{~mm}$ could be attributed to the loss of MIR radiation on the sides of the drying zone. By reducing the height of the emitters below $80 \mathrm{~mm}$, the radiations losses could be reduced to an insignificant level, leading to the same energy consumption when the emitters were placed 50 and $80 \mathrm{~mm}$ above the belt.

\section{Effect of the suction airflow rate}

The effect of the suction airflow rate on drying was studied under two different cases, as shown in Fig. 11. For these tests, the emitter height was maintained constant at $115 \mathrm{~m}$ above the belt. In the first case, the MIR intensity was maintained at $50 \%$ and the airflow rate at $18.3 \mathrm{~m}^{3} / \mathrm{s}$. The damper valve was then partially closed to reduce the airflow rate from 18.3 to $11.1 \mathrm{~m}^{3} / \mathrm{s}$, while MIR intensity remained constant at $50 \%$. This caused the drying temperature to drop from $136^{\circ} \mathrm{C}$ to $156^{\circ} \mathrm{C}$ due to a reduced cooling effect from the suction air (which is at ambient temperature, so at a temperature considerably lower than the pellets). In the second case, the emitter intensity was reduced to achieve a constant temperature in the drying zone, after decreasing the airflow rate from 18.3 to $11.1 \mathrm{~m}^{3} / \mathrm{s}$.

At constant MIR intensity, the drying curves were similar for the different airflow rates. These were, however, different when drying temperature was maintained constant at an airflow rate of $11.1 \mathrm{~m}^{3} / \mathrm{s}$. The results in the former case suggest that the higher suction airflow rate led to a higher mass transfer rate but also a greater cooling effect. These effects counterbalanced so that the drying curves were not significantly different. On the contrary, by maintaining a constant drying temperature, the higher airflow rate caused a higher mass transfer rate without inducing a cooling effect, leading to a higher drying rate. After drying for $20 \mathrm{~min}$ at a constant drying temperature of approximately $136^{\circ} \mathrm{C}$, the moisture content was 0.8 and $0.4 \mathrm{~g}$ water/g dry solid at an airflow rate of 11.1 and $18.3 \mathrm{~m}^{3} / \mathrm{s}$ respectively.

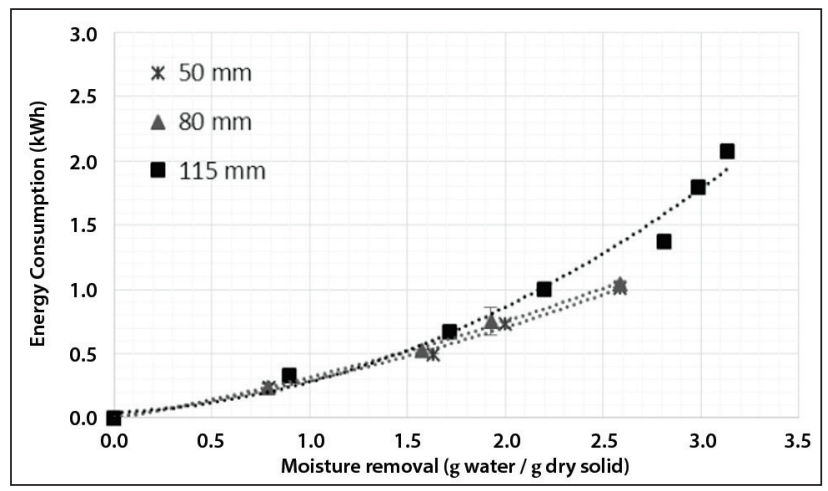

Figure 10. Energy consumption as a function of moisture removal at different emitter height above the belt

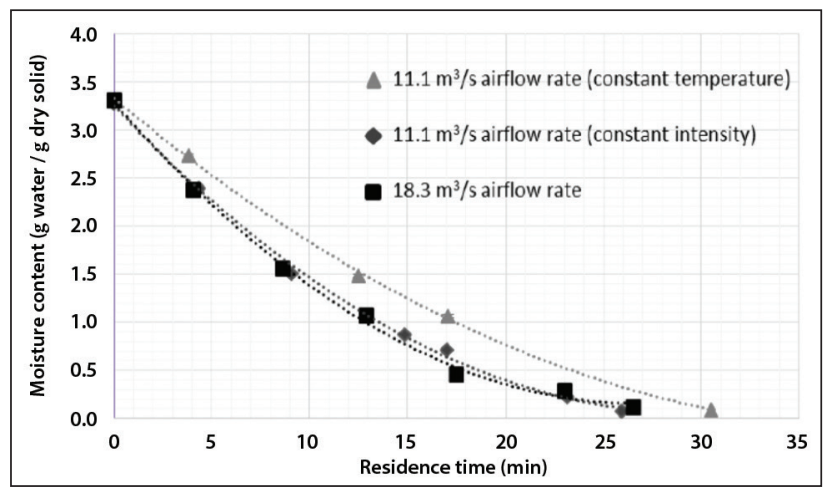

Figure 11. Drying curves for different airflow rates 
These results illustrate the positive effect of the suction airflow in terms of mass transfer, but negative effect with respect to heating. Pre-heating the suction airflow could be an interesting option, as it would eliminate the cooling effect on the pellets, thus possibly increasing the drying rates and reducing the drying times.

\section{Effect of pellet diameter}

The influence of pellet size was investigated at an MIR intensity of $50 \%$, suction airflow rate of $18.3 \mathrm{~m}^{3} / \mathrm{s}$ and an emitter height above the belt of $115 \mathrm{~mm}$.

The drying curves for different pellet diameters are presented in Fig. 12. Pellets with a larger size had longer drying times compared to those with smaller size, as could be expected. The $14 \mathrm{~mm}$ pellets had the longest drying time, followed by the 12,10 and finally $8 \mathrm{~mm}$ pellets. At a residence time of $25 \mathrm{~min}$, pellets with a diameter of $8 \mathrm{~mm}$ were dried to a moisture content below $0.5 \mathrm{~g}$ water/g dry solid (33\% wet basis) while the pellets with a diameter of $14 \mathrm{~mm}$ had a moisture content of $1.2 \mathrm{~g}$ water/g dry solid (55\% wet basis). These results are consistent with previous studies where drying time increases with increasing sample thickness (Liu et al., 2014; Swasdisevi et al., 2007). This trend can be explained by the decrease of heat and mass transfer rates with the increase of sample size (Krishnamurthy et al., 2008).

Figure 13 displays the drying rate curves for 8 and $14 \mathrm{~mm}$ diameter pellets at an MIR intensity of $50 \%$, suction airflow rate of $18.3 \mathrm{~m}^{3} / \mathrm{s}$. The drying rate decreased from 0.22 to 0.13 for the $8 \mathrm{~mm}$ pellets, whereas it remained fairly constant around $0.1 \mathrm{~g}$ water/min for 8 and $14 \mathrm{~mm}$ diameter pellets respectively.

The temperature measurements in the pellets could give a better insight into this. In the case of the $8 \mathrm{~mm}$ pellets, the external surface temperature constantly increased, so it is likely that the constant rate period is short or non-existent, and drying occurred mostly in the falling rate period. In the case of the $14 \mathrm{~mm}$ pellets,

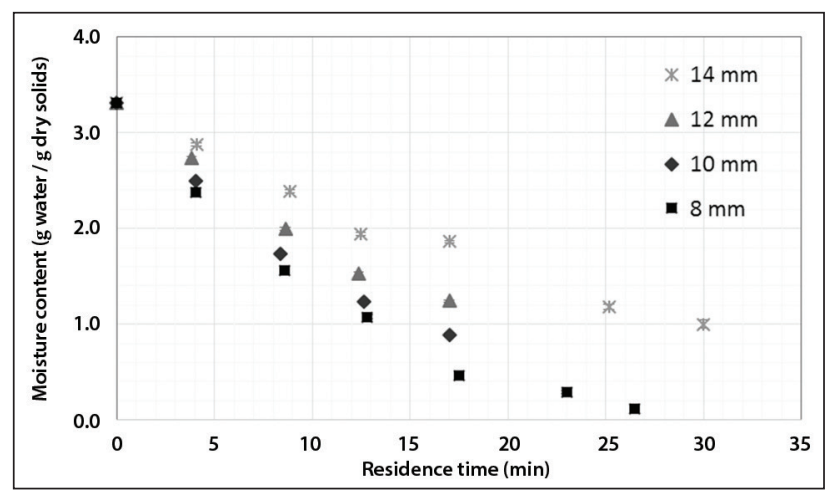

Figure 12. Drying curves for different pellet diameters

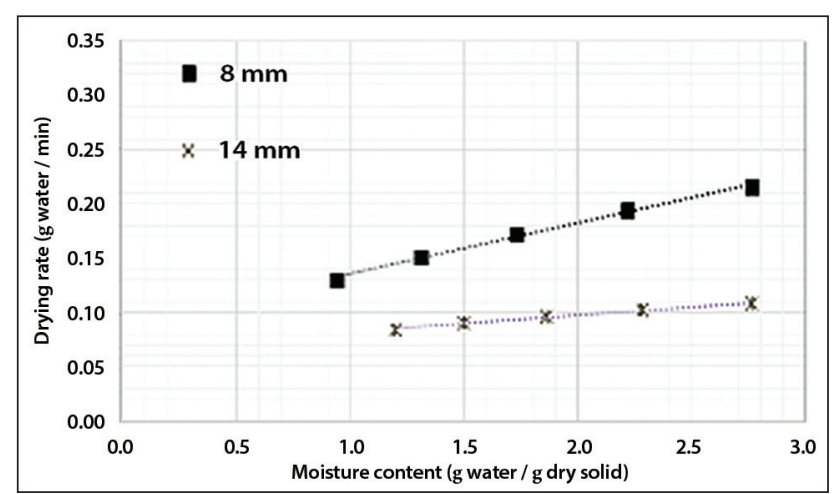

Figure 13. Drying rate as a function of moisture content for different pellet diameters the temperature at the surface was constant during the first 12 min before it started to increase. Therefore, it can be assumed that the constant rate period occurs until a moisture content of approximately $2 \mathrm{~g}$ of water/g dry solid (12 min of residence time) is reached; then the falling rate period started. Figure 14 presents the energy consumption as a function of moisture content removal during drying of pellets of different diameters. To reduce the moisture content to $1.5 \mathrm{~g}$ water/g dry solid, the energy consumption was $1.3,0.8,0.6$ and $0.5 \mathrm{kWh}$ for pellet diameters of $14,12,10$ and $8 \mathrm{~mm}$, respectively. This result shows that the energy consumption is lower for the drying of smaller diameter pellets. Indeed, the heat and mass transfers occur more efficiently as the size of the material is low.

\section{Effect of different types of samples}

The drying behaviour of different types of sample (raw sludge, sludge mixed with sawdust, sludge pre-dried to $2.1 \mathrm{~g}$ water/g dry solid) is shown in Fig. 15. The drying curves were normalised with respect to the initial moisture content for a better comparison of the graphs, as the initial moisture content was different for the different samples. In these experiments, the height of the two emitters above the belt was set at $115 \mathrm{~mm}$, the emitter intensity at $50 \%$, and the suction airflow rate at $18.3 \mathrm{~m}^{3} / \mathrm{s}$, for the $8 \mathrm{~mm}$ pellets.

There was no significant difference between the drying curves of the different samples. This suggests that pre-drying and addition of sawdust did not influence the drying kinetics.

\section{CONCLUSION}

This study shows that drying in the LaDePa machine can be influenced by various parameters, including the MIR intensity, emitter height, airflow rate, drying time and pellet size.

The measurement of the temperature at the surface and core of pellets revealed that drying within the pellet was not isothermal

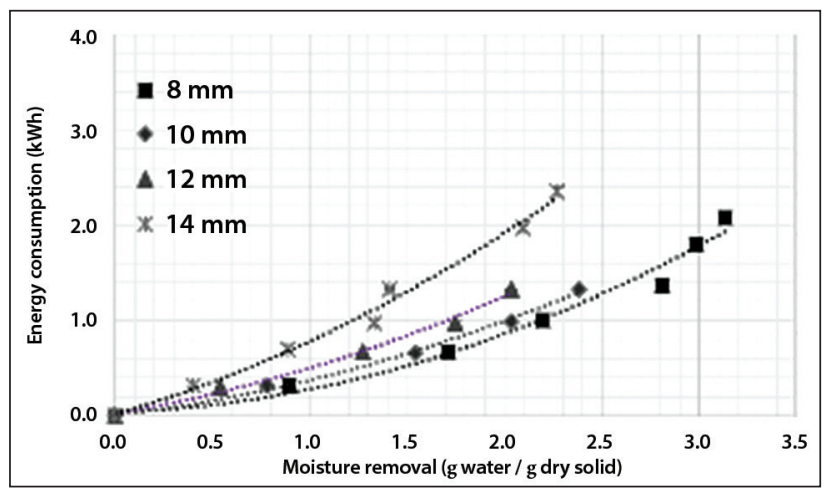

Figure 14. Energy consumed as a function of moisture removal for different pellet diameters

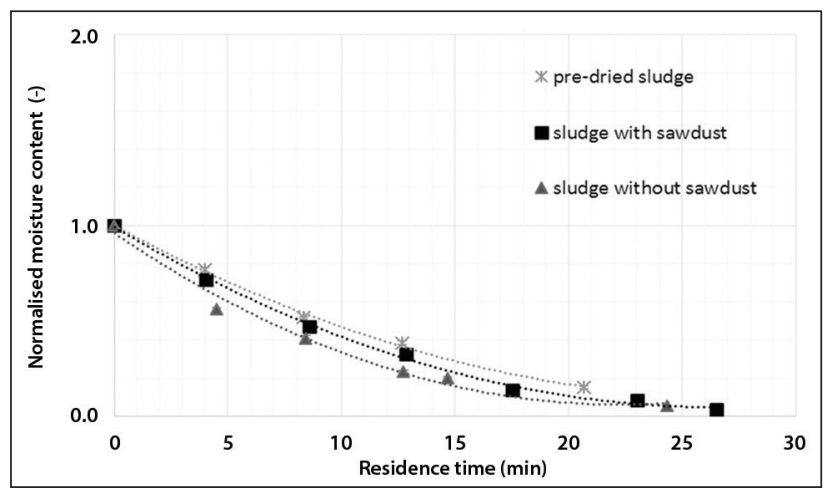

Figure 15. Drying curves for different types of samples 
and the surface dried faster than the core. At a lower heat flux (low MIR intensity, large pellet size), part of the drying probably occurred in the constant rate period, whereas at a higher heat flux, the entire drying process likely occurred in the falling rate period.

The increase of the MIR intensity led to an increase of the drying temperature, resulting in higher drying rates and performance. However, when the MIR intensity is too high, thermal degradation can occur, which could be avoided by reducing the residence time. It is therefore advisable to dry at the highest possible MIR intensity and shortest residence time before thermal degradation occurs.

Similar drying temperatures can be obtained by different combinations of MIR intensity and emitter height, leading to similar results in terms of the drying rate. Therefore, it is recommended that the lowest possible emitter height with respect to the belt be used, in order to minimize the running costs associated with the operation of the MIR emitters.

Increase in airflow rate leads to an increase in mass transfer. This, however, causes a greater cooling effect that has a negative effect on the drying rate. An optimal air flowrate should therefore be selected such that mass transfer is maximised while the cooling effect is minimised. It would be beneficial to use preheated air in the instance of increased airflow rate, which would enhance the mass transfer without leading to a cooling effect.

Decreasing the pellet size leads to higher drying rates and lower energy demand. Therefore, the size of pellets should be as small as possible, but this would depend on the ability of the extruder to achieve small-sized pellets.

Pre-drying of the sludge and addition of sawdust did not have a significant influence on drying kinetics. Sawdust could thus be added to the faecal sludge to improve extrusion and improve the pellet consistency, without altering the drying behaviour of the material.

\section{ACKNOWLEDGEMENTS}

The research presented in this paper was funded by the Water Research Commission (WRC), as part of WRC Project No. K5/2137: Characterisation of on-site sanitation materials and products.

\section{REFERENCES}

ARTHUR R, BAIDOO MF, BREW-HAMMOND A and BENSAH EC (2011) Biogas generation from sewage in four public universities in Ghana: A solution to potential health risk. Biomass Bioenerg. 35 (7) 3086-3093. https://doi.org/10.1016/j.biombioe.2011.04.019

BHAGWAN J, STILL D, BUCKLEY C and FOXON K (2008) Challenges with up-scaling dry sanitation technologies. Water Sci. Technol. $\mathbf{5 8}$ (1) 21-27. https://doi.org/10.2166/wst.2008.606

CSERTA E (2012) Drying process of wood using infrared radiation. PhD thesis, University of West Hungary, Bajcsy-ZsilinsZky, Sopron, Hungary.
DIENER S, ZURBRÜGG C, GUTIÉRREZ FR, NGUYEN DH, MOREL A, KOOTTATEP T and TOCKNER K (2011) Black soldier fly larvae for organic waste treatment-prospects and constraints. In: Alamgir M, Bari QH, Rafizul IM, Islam SMT, Sarkar G and Howlader MK (eds) Proceedings of the WasteSafe $2011-2^{\text {nd }}$ International Conference on Solid Waste Management in the Developing Countries, 13-15 February 2011, Khulna, Bangladesh. https://doi.org/10.1007/s12649011-9079-1

HEBBAR HU, VISHWANATHAN KH and RAMESH MN (2004) Development of combined infrared and hot air dryer for vegetables. J. Food Eng. 65 (4) 557-563. https://doi.org/10.1016/j.jfoodeng.2004. 02.020

KRISHNAMURTHY K, KHURANA HK, SOOJIN J, IRUDAYARAJ J and DEMIRCI A (2008) Infrared heating in food processing: an overview. Compr. Rev. Food Sci. Food Saf. 7 (1) 2-13. https://doi. org/10.1111/j.1541-4337.2007.00024.x

LI Q, ZHENG L, CAI H, GARZA E, YU Z and ZHOU S (2011) From organic waste to biodiesel: Black soldier fly, Hermetia illucens, makes it feasible. Fuel 90 1545-1548. https://doi.org/10.1016/j. fuel.2010.11.016

LIU Y, ZHU W, LUO L, LI X and YU H (2014) A mathematical model for vacuum far-infrared drying of potato slices. Drying Technol. 32 (2) 180-189. https://doi.org/10.1080/07373937.2013.811687

MENG X, STEINE M, MIRARA S and DE JONG W (2014) Experimental study of drying different sludges using a belt-MIR LaDePa dryer. Paper presented at: $22^{\text {nd }}$ European Biomass Conference and Exhibition, 23-26 June 2014, Delft. 1073-1077.

MONGPRANEET S, ABE T and TSURUSAKI T (2004) Kinematic model for a far infrared vacuum dryer. Drying Technol. 22 (7) 1675-1693. https://doi.org/10.1081/DRT-200025628

PAN Z, SHIH C, MCHUGH TH and HIRSCHBERG E (2008) Study of banana dehydration using sequential infrared radiation heating and freeze-drying. LWT - Food Sci. Technol. 41 (10) 1944-1951. https:// doi.org/10.1016/j.lwt.2008.01.019

RATTI C and MUJUMDAR A (1995) Infrared drying. Handbook of Industrial Drying (Vol. 1). CRC Press, Boca Raton. 567-588.

SEPTIEN S, SINGH A, MIRARA S, TEBA L, VELKUSHANOVA $\mathrm{K}$ and BUCKLEY C (2018) ' $\mathrm{LaDePa}$ ' process for the drying and pasteurization of faecal sludge from VIP latrines using infrared radiation. S. Afr. J. Chem. Eng. 25 147-158. https://doi.org/10.1016/ j.sajce.2018.04.005

SEVILLA M and FUERTES AB (2009) The production of carbon materials by hydrothermal carbonization of cellulose. Carbon 47 (9) 2281-2289. https://doi.org/10.1016/j.carbon.2009.04.026

SHARMA GP, VERMA RC and PATHARE PB (2005) Thin-layer infrared radiation drying of onion slices. J. Food Eng. 67 (3) 361-366. https://doi.org/10.1016/j.jfoodeng.2004.05.002

STILL D and FOXON K (2012) Tackling the challenges of full pit latrines. WRC Report No. 1745/1/12. Water Research Commission, Pretoria.

SWASDISEVI T, DEVAHASTIN S, NGAMCHUM $\mathrm{R}$ and SOPONRONNARIT S (2007) Optimization of a drying process using infrared-vacuum drying of Cavendish banana slices. Optimization 29 (3) 810.

WILLIAMS PT (2013) Waste Treatment and Disposal. John Wiley \& Sons, West Sussex. 